\title{
Conxita Domènech y Andrés Lema-Hincapié (Eds.). El segundo Quijote (1615): Nuevas interpretaciones cuatro siglos después (2015). Madrid: Iberoamericana/Vervuert, 2018, 414 páginas
}

\author{
Meredith Lyn Jeffers
}

Jeffers, M. L. (2021). Conxita Domènech y Andrés Lema-Hincapié (Eds.). El segundo Quijote (1615): Nuevas interpretaciones cuatro siglos después (2015). Madrid: Iberoamericana/Vervuert, 2018, 414 páginas. Revista de Filología y Lingüística de la Universidad de Costa Rica, 47(1), e44471. doi: https://doi.org/10.15517/rfl.v47i1.44471

\section{(9) $\mathbb{P Q \Theta \Theta}$}

Doi: https://doi.org/10.15517/rfl.v47i1.44471

URL: https://revistas.ucr.ac.cr/index.php/filyling/index 


\section{Reseñas}

Conxita Domènech y Andrés Lema-Hincapié (Eds.).El segundo Quijote (1615): Nuevas interpretaciones cuatro siglos después (2015). Madrid: Iberoamericana/Vervuert, 2018, 414

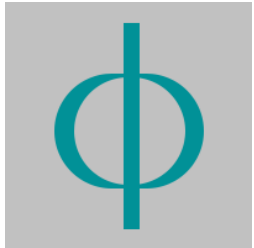
páginas

\section{Jeffers, Meredith Lyn}

(D) Meredith Lyn Jeffers mjeffer8@msudenver.edu

Universidad Estatal Metropolitana de Denver, Denver, Colorado, Estados Unidos

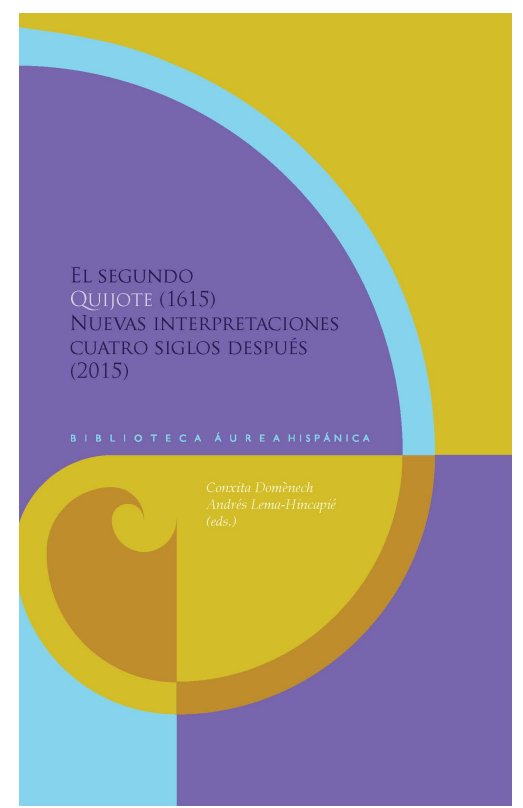

Domènech ConxitaLema-Hincapié Andrés. El segundo Quijote

(1615): Nuevas interpretaciones cuatro siglos después (2015). 2018.

Madrid. Iberoamericana/Vervuert. 414 páginaspp.

Revista de Filología y Lingüística de la Universidad de Costa Rica

Universidad de Costa Rica, Costa Rica

ISSN: 0377-628X

ISSN-e: 2215-2628

Periodicidad: Semestral

vol. 47, núm. 1, 2021

filyling@gmail.com

URL: http://portal.amelica.org/ameli/ jatsRepo/125/1251597027/index.html

DOI: https://doi.org/10.15517/rf.v47i1.44471 
Esta obra colectiva, coordinada por los profesores Conxita Domènech y Andrés Lema-Hincapié, inaugura una nueva etapa en la investigación del segundo tomo de El ingenioso bidalgo don Quijote de la Mancha (1615) de Miguel de Cervantes y Saavedra. Los trabajos que componen este libro son el resultado de un congreso internacional, organizado por los mismos editores en 2015, el cual conmemoraba el aniversario número cuatrocientos de la Segunda Parte. Tal como precisa el título, los autores buscan presentar nuevas interpretaciones de la obra maestra de Cervantes. Y, juntos, logran "seducir a un cada vez mayor número de lectores” al responder detalladamente a una pregunta fundamental: ¿qué puede seguir diciendo el segundo libro del Quijote algunos cuatrocientos años después?

La obra colectiva reúne un total de quince trabajos, divididos en cinco secciones. En la primera ("Segunda parte del Quijote: vientos de guerra, de ficción y de muerte”) se presentan trabajos centrados en las experiencias de Cervantes, el Quijote como alegoría de ficción y la muerte como gran pregunta metafísica; en la segunda ("Este también es el libro de Sancho") se incluyen trabajos más o menos dedicados al personaje de Sancho Panza; en la tercera ("Géneros visuales y literarios en diálogo con el Quijote") se discute sobre las posibles influencias en el Quijote y sobre las interrelaciones entre literatura, cine, teatro, música y teatro de títeres; en la cuarta ("El Quijote y sus cuestiones humanísticas") se abordan cuestiones de la política médica, la teología y la moral; y en la quinta ("El Quijote como una obra maestra de Cataluña") se estudia lo que representa Cataluña para la conclusión de la novela y para la continuación de la historia de España después de la publicación del segundo libro. Aunque esta antología crítica cuenta con la colaboración de algunos de los más reconocidos investigadores del Quijote y del Siglo de Oro de España, cada trabajo recogido en esta obra supone un gran aporte al estudio del Quijote en el siglo veintiuno. También jacta de exquisitas ilustraciones y fotografías, las cuales sirven para apreciar la gran diversidad del imaginario colectivo del Quijote.

La primera sección abre con el ensayo de Diana de Armas Wilson, "Cervantes y los piratas de la Berbería”. Además de explorar la gran importancia del mar Mediterráneo para la vida y la novela de Cervantes, de Armas Wilson presenta abundante información sobre los piratas, los corsarios y la experiencia del mismo Cervantes como soldado y luego preso durante la época del apogeo del corso en el Mediterráneo. El ensayo incluye hechos recogidos por el doctor Sosa, un clérigo portugués que fue compañero de Cervantes en el cautiverio, así como retrata la figura del corsario Morato Arraéz, quien luchó en la famosa batalla de Lepanto que luego dio paso al apodo de Cervantes. Aquí se plasma con todo detalle una nueva imagen de Cervantes; una que, después de leer esta contribución, resulta estar inevitable e inextricablemente vinculada a la voz al timón del Quijote. El segundo capítulo, "Interacción entre ficción y realidad: algunas diferencias entre la Primera y la Segunda partes del Quijote”, escrito por Álvaro Bautista-Cabrera, presenta las dos partes del Quijote como una alegoría de nuestra lectura de ellas. Es decir, Bautista-Cabrera postula que lo que le pasa a Alonso Quijano es precisamente lo que nos pasa a nosotros como lectores de ficción. Con mucha destreza, se describe cómo el viaje de don Quijote, de ida y vuelta, a lo largo de las dos partes de la novela, imita nuestra inmersión en la historia de ficción y también nuestro regreso al mundo real una vez que llegamos al fin. En el último capítulo de la primera sección, "Las muchas muertes de Alonso Quijano el Bueno”, el editor Andrés Lema-Hincapié también medita en las muchas muertes del segundo libro del Quijote, estudiando "qué sentidos existenciales tendrían los detalles y el modo según los cuales muere” el querido don Quijote, y concluyendo que tal vez también muere la primera novela de la Modernidad, para la cual Cervantes podría ser pensado como padre, asesino y enterrador.

La segunda sección comienza con el ensayo "Avellaneda y la crisis de autoridad en la Segunda Parte del Quijote", elaborado por Edwin Williamson. Aquí Williamson retoma un hilo fundamental -autoridad/ autoría - situando las cambiantes dinámicas de poder entre Quijote y Sancho paralelas a las de Cervantes y Avellaneda, el autor del Quijote apócrifo que es ridiculizado y relegado por Cervantes en la Segunda Parte. 
Argumenta que estas dinámicas entran en crisis en la Segunda Parte; una crisis tanto política como literaria, y una en la cual se plasma la esencia moderna de la novela. En el próximo ensayo, Jennifer Brady ofrece una lectura minuciosa de lo que denomina "la formación teatral" de Sancho Panza. Este capítulo es el más dedicado a la figura de Sancho, y el que mejor justifica el título de la sección. Brady presenta una nueva interpretación de cómo la identidad, la subjetividad y la agencia de Sancho se desarrollan a través de sus roles como "actor" y "director" teatral del mundo ficticio, particularmente en la Segunda Parte. Aunque don Quijote sea el protagonista titular de la obra cervantina, la autora de este ensayo muestra que el escudero no es secundario en ningún sentido. Para terminar la segunda sección, José Reinel Sánchez reflexiona sobre las muchas referencias a los animales, particularmente como sujetos de los refranes de Sancho.

En la tercera sección se encuentran cuatro ensayos, lo cual, a primera vista, parece desequilibrar la disposición del libro. No obstante, las muchas posibles influencias del Quijote, combinadas con su amplio impacto en posteriores obras de arte, cine, literatura, música y teatro más que justifican la presencia del capítulo adicional. En el primero, Michael Paul Abeyta discute el género literario árabe de las maqāmāt como precursoras de la picaresca, citando el profundo conocimiento de Cervantes del mudejarismo. Este ensayo se remonta al primer capítulo de la primera sección, ofreciendo otra perspectiva sobre la relación entre la vida y la literatura de Cervantes. Nelson Orringer luego explora el episodio de maese Pedro, mostrando cómo "la malaventura de Melisendra" cuestiona los mismos temas de autoridad y autoría presentados por Williamson en la sección dos. Orringer analiza cómo el episodio afectó la manera en que Federico García Lorca ayudó a adaptar el retablo para la ópera de títeres de Manuel de Falla, El retablo de maese Pedro, estrenada en 1923, y también la manera en que maese Pedro figuró en su propia farsa La zapatera prodigiosa $(1930,1933)$ y en el drama Elpúblico (1930). En el tercer ensayo, "La actuación de don Quijote en el retablo de maese Pedro: una expresión temprana de la libertad en sentido negativo", Carlos-Germán van der Linde ofrece una lectura cuidadosa de la misma escena de maese Pedro, recordando que este es Ginés de Pasamonte de la Primera Parte, e insistiendo que, no solo por eso, cabe destacar la conexión entre los dos episodios. Es una tesis bien pensada, y van der Linde hace bien en trazar las líneas entre los episodios del galeote, el retablo y la cueva de Montesinos para iluminar los temas de verdad, ficción y libertad absoluta. Para terminar la sección, en el ensayo "El Quijote y los wésterns", Jorge Latorre y Oleksandr Pronkevich combinan sus fuerzas para analizar el arquetipo del mito quijotesco presente en numerosos wésterns del cine americano. Gracias a este trabajo se consigue apreciar qué tan lejos se puede llevar el Quijote, y cómo sigue adaptándose a diferentes medios, culturas y tiempos.

La cuarta sección es la más desafiante para los lectores que no son especialistas en el Siglo de Oro español. Afortunadamente, las notas de cada ensayo, junto con los cuatro índices al final de la antología -de obras, de nombres, de conceptos y de ilustraciones- permite que los lectores menos familiarizados comprendan la riqueza de información. En el primer ensayo de esta sección, "El tomismo del Quijote II: reflexiones sobre la virtud en tres personajes quijotescos”, Michael J. McGrath lee el segundo tomo del Quijote a través del prisma de Summa Theologica (1265-1275) de Tomás de Aquino, catalogando las virtudes y los vicios de los personajes para así entender su comportamiento y sus motivos. En el segundo ensayo, "La medicina política en Cervantes: el gobierno del cuerpo en el Quijote de 1615”, la autora Julia Domínguez examina la interrelación entre la medicina y la política, prestando atención especial al gobierno de Sancho de la ínsula Barataria. Y en el último ensayo, "Quijote II, 33-36, de la prudencia a la sanción moral: 'no es oro todo lo que reluce' y 'la codicia rompe el saco", Jorge Chen Sham nos permite explorar la metáfora monetaria de Sancho, la cual empieza en casa de los Duques, cuando Sancho emplea el refrán "no es oro todo lo que reluce", y termina con la Duquesa, quien declara que "la codicia rompe el saco". El ensayo complementa los estudios de Sancho en otras partes de libro, mientras clausura el estudio de estas tres disciplinas humanísticas en el Quijote.

La última sección es quizás la más impactante, pese al hecho de que solo cuenta con dos ensayos. En el primero, "Don Quijote en Barcelona: una explicación del viaje a Cataluña”, Antonio M. Rueda Sancho 
examina el viaje a Cataluña como un ejercicio de memoria realizado por el propio Cervantes, quien, tal como su protagonista, viajó a Barcelona al final de su vida. Quizás, propone Rueda, tal viaje resonaba con la imposibilidad de regresar al pasado, y por eso, el Quijote termina con un abatido Alonso Quijano. La editora Conxita Domènech concluye la obra colectiva mostrando que la experiencia de don Quijote en Cataluña presagia la verdadera desilusión y muerte que tuvieron lugar después de que el rey Felipe IV y su conde-duque de Olivares emprendieron la misma ruta en 1626. Si uno lee esta obra colectiva según el orden de la tabla de contenido, el ensayo de Domènech es incluso más poderoso: después de estudiar cómo el Quijote fue producto de su autor y su tiempo, y después de ver cómo el Quijote produjo un sinfín de adaptaciones, aproximaciones, lecturas y teorías -incluso cuatrocientos años después - no es de sorprender que el Quijote también lograra anunciar la historia verdadera de España.

En definitiva, los trabajos recogidos en esta obra demuestran que la segunda parte del Quijote merece más atención. Aunque la segunda parte del Quijote ha sido eclipsada por la primera parte durante cuatrocientos años, y aunque es, por ahora, la menos conocida de las dos, los autores de El segundo Quijote (1615): Nuevas interpretaciones cuatro siglos después iluminan la profundidad y riqueza de esta obra cervantina y abren la puerta a futuras investigaciones. Mientras tanto, esta antología crítica sirve como una excelente fuente, tanto para los estudiantes graduados avanzados como para los especialistas en Cervantes, el Quijote y el Siglo de Oro. 